Proceedings of the International Symposium on Physics of Materials (ISPMA 14), September 10-15, 2017, Prague

\title{
The Effect of Pile-Up on Indentation Hardness Evaluation of Neutron-Irradiated 15Ch2MFA Steel
}

\author{
A. Materna ${ }^{a, *}$, P. HAušIlld ${ }^{a}$, J. OndrÁČEK ${ }^{a}$ And M. KytKa ${ }^{b}$ \\ ${ }^{a}$ Czech Technical University in Prague, Faculty of Nuclear Sciences and Physical Engineering, \\ Department of Materials, Trojanova 13, 12000 Praha 2, Czech Republic \\ ${ }^{b}$ Rež Nuclear Research Institute, Husinec-Řě, Hlavní 130, 250 68, Czech Republic
}

\begin{abstract}
Hardness testing is an efficient means for monitoring the change in mechanical properties of irradiated materials. The evaluation of the indentation load-displacement data is commonly based on the Oliver-Pharr method, which estimates the projected contact area between the indenter tip and the material surface using Sneddon's elastic contact solution. This simplified method can lead to significant errors when the indented elastic-plastic material exhibits extensive pile-up around the indenter, which is typical for a material with a smaller strain-hardening exponent $n$ and a smaller yield strength-to-elastic modulus ratio $\sigma_{y} / E$. Since both these mechanical properties are influenced by the neutron irradiation, one must be careful with the interpretation of measured indentation hardness. In this study, a finite element simulation was used to investigate the effect of pile-up on indentation hardness evaluation. Load-displacement curves, contact areas evaluated by both Oliver-Pharr method and finite element nodes in contact and the corresponding hardnesses were obtained for the $15 \mathrm{Ch} 2 \mathrm{MFA}(15 \mathrm{Cr} 2 \mathrm{MoV})$ tempered bainitic steel in non-irradiated and neutron-irradiated state. The Oliver-Pharr method underestimates the true contact area, and therefore overestimates hardness by factor of 1.32 and 1.40 for non- and neutron-irradiated state, respectively. Despite this discrepancy, the Oliver-Pharr method as well as direct observation of the contact area are able to indicate the increase of hardness due to neutron-irradiation ( $15 \%$ vs. $8 \%$ increase in hardness).
\end{abstract}

DOI: 10.12693/APhysPolA.134.729

PACS/topics: $81.40 . \mathrm{Np}, 61.80 . \mathrm{Hg}$

\section{Introduction}

Radiation embrittlement of key parts of pressurized water reactors (PWRs) is limiting factor for safe operation of nuclear power plants [1]. Post-irradiation annealing at proper condition can result in partial to nearly full embrittlement recovery [2]. Despite the progress in predicting irradiation embrittlement and recovery [3-5], extensive material testing is still required for description of the recovery process.

The presented work is a part of a long-term effort to find optimal annealing condition for WWER-type reactor pressure vessel [6] as well as reactor core internals [7]. To achieve this goal, a reliable measure of material properties recovery must be used. The degree of material damage or subsequent recovery can be monitored through the change in mechanical properties, because the irradiated material exhibits an increase in the brittle to ductile transition temperature, an increase in hardness, increases in both the yield strength and ultimate tensile strength, and a decrease in ductility. Especially hardness testing may be advantageous because of the small sampling volume requirement.

Recently, the depth sensing indentation test became a widely used method for the determination of the hardness. The evaluation of the indentation load - displacement data is commonly based on the Oliver-Pharr (OP)

*corresponding author; e-mail: ales.materna@fjfi.cvut.cz method $[8,9]$ which estimates the projected contact area between the indenter tip and the material surface using Sneddon's elastic contact solution [10]. This simplified method can lead to significant errors when the indented elastic-plastic material exhibits extensive pile-up around the indenter.

In this paper, a numerical study of instrumented hardness test with the Berkovich indenter and 15Ch2MFA steel in non-irradiated and neutron-irradiated state is presented and the effect of so-called pile-ups on indentation hardness evaluation is examined.

\section{Material}

The steel chosen for this study was the 15Ch2MFA $(15 \mathrm{Cr} 2 \mathrm{MoV})$ tempered bainitic steel used for fabrication of pressure vessels of WWER 440-type nuclear reactors. The results of standard tensile tests for non-irradiated and irradiated state after neutron fluence $\Phi_{n}=9.5 \times$ $10^{23} \mathrm{~nm}^{-2}$ were available from previous research [11, 12] and are summarized in Table I. Work-hardening curves were characterized by the power-law relationship $\sigma=$ $K \varepsilon_{p l}^{n}$ in true stress $\sigma$-true plastic strain $\varepsilon_{p l}$ terms.

\section{Evaluation of hardness}

The hardness $H$ measured by instrumented indentation during one cycle of loading and unloading is defined as maximum load in cycle $P_{\max }$ divided by the contact area under load $A$ : 


$$
H=\frac{P_{\max }}{A} .
$$

According to the Oliver-Pharr method, contact area is estimated from the maximum load in the cycle $P_{\max }$, the maximum displacement $h_{\max }$ and the elastic unloading stiffness $S=d P / d h$ defined as the slope of the upper part of the unloading curve:

$$
A=\pi\left(h_{\max }-0.72 \frac{P_{\max }}{S}\right)^{2} \tan ^{2} 70.3^{\circ}
$$

(for detailed explanation see [9]). However, in case of elastic-plastic material response, material piles up around the indenter (Fig. 1) and the contribution of the piled-up contact area is not included in the OP analytical approach. This underestimation of contact area is more significant when the material does not appreciably workharden. Depending on the extent of the pile-up, the hardness can be overestimated by as much as $60 \%$ [13]. Therefore, the contact area at maximum load was also obtained directly from the numerical simulation.

\section{TABLE I}

Mechanical properties obtained from tensile tests of non-

\begin{tabular}{|c|c|c|c|c|}
\hline \multirow[b]{2}{*}{$\begin{array}{c}\text { Neutron } \\
\text { fluence } \Phi_{n} \\
{\left[\mathrm{n} \mathrm{m}^{-2}\right]}\end{array}$} & \multirow[b]{2}{*}{$\begin{array}{l}\text { Yield } \\
\text { stress } \\
{[\mathrm{MPa}]}\end{array}$} & \multirow[b]{2}{*}{$\begin{array}{c}\text { Tensile } \\
\text { strength } \\
{[\mathrm{MPa}]}\end{array}$} & \multicolumn{2}{|c|}{$\sigma=K \varepsilon_{p l}^{n}$} \\
\hline & & & $\begin{array}{c}\text { Strain } \\
\text { hardening } \\
\text { parameter } K \\
\text { [MPa] }\end{array}$ & $\begin{array}{c}\text { Strain } \\
\text { hardening } \\
\text { exponent } n\end{array}$ \\
\hline 0 & 560 & 670 & 875 & 0.085 \\
\hline $9.5 \times 10^{23}$ & 710 & 785 & 880 & 0.042 \\
\hline
\end{tabular}
end neutron-irradiated 15Ch2MFA steel

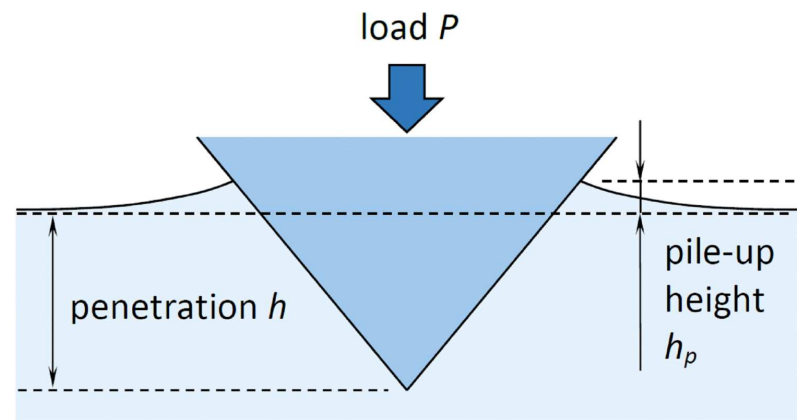

Fig. 1. Cross-section of an indentation profile showing pile-up height $h_{p}$.

\section{Numerical simulations}

Nonlinear finite element simulations of the indentation test and the estimation of load-displacement curve were performed in commercial code MSC.Marc.

The goal of the numerical study was to quantify the effect of material pile-up on reliability of the contact area evaluation by the OP method. Therefore, the contact areas have been evaluated from simulated indentation loaddisplacement curves and compared with "true" contact areas obtained directly from a finite element analysis.
Three various indenter geometries have been studied: (i) a three-dimensional real shape Berkovich three-sided pyramid to account for a real shape of imprint and pileup profile, (ii) a three-dimensional cone to compare real and simplified equivalent geometry on the same 3D finite element mesh, (iii) two-dimensional axisymmetric geometry with equivalent cone to compare $3 \mathrm{D}$ and $2 \mathrm{D}$ fine mesh results. The equivalent cone apex angle has been set to $70.3^{\circ}$ and was chosen to have the same ratio of projected contact area per penetration depth.

3 D finite element mesh (Fig. 2 ) covers $1 / 6$ of the whole geometry and the rest was modelled by the symmetric boundary conditions. The specimen was also fixed on its bottom in all directions. The specimen height and diameter are respectively considered to be 100 times and 50 times the imprint height and length, which minimizes the effect of boundary conditions on its exterior on the achieved results. 2D axisymmetric model roughly corresponds to the $3 \mathrm{D}$ one except the three times smaller size of the fine elements under the indenter. The contact area is then covered approximately by 200 quadrilateral linear finite elements.

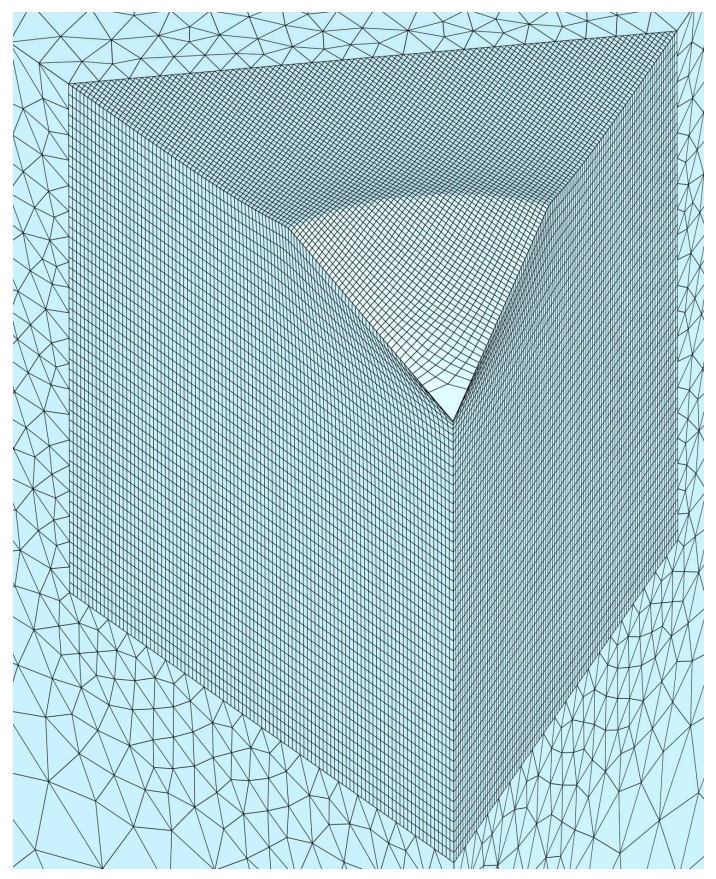

Fig. 2. Deformed 3D finite element mesh under the conical indenter.

Indentation was driven by the force with the same maximum $300 \mathrm{~N}$ for all simulations, but due to self-similarity of the Berkovich indenter the value of maximum force has no influence on relative comparison of achieved results.

The indenter was treated as rigid, the contact between the indenter and indented material was frictionless.

Elastic properties of material 15Ch2MFA were characterized by the Young modulus $E=200000 \mathrm{MPa}$ and Poisson's ration $\nu=0.3$. Plastic properties were set up according to Table I. Large strain framework was used. 
Numerically determined maximum penetration depths, contact areas and maximum

TABLE II pile-up heights for three various analysis types and two material states

\begin{tabular}{l|c|l|c|c|c}
\hline \hline \multirow{2}{*}{ Indenter shape } & Analysis dimension & Material state & $h_{\max }[\mu \mathrm{m}]$ & $A\left[\mathrm{~mm}^{2}\right]$ & $\begin{array}{c}\text { Maximimum pile-up } \\
\text { height } h_{p}[\mu \mathrm{m}]\end{array}$ \\
\hline \multirow{2}{*}{ Berkovich } & \multirow{2}{*}{$3 \mathrm{D}$} & non-irradiated & 72 & 0.158 & 15 \\
& & neutron-irradiated & 68 & 0.146 & 18 \\
\hline \multirow{3}{*}{ equivalent cone } & \multirow{2}{*}{$3 \mathrm{D}$} & non-irradiated & 72 & 0.157 & 11 \\
\cline { 2 - 6 } & \multirow{2}{*}{$2 \mathrm{D}$} & neutron-irradiated & 67 & 0.143 & 12 \\
& & non-irradiated & 71 & 0.155 & 8.4 \\
& neutron-irradiated & 68 & 0.143 & 9.6
\end{tabular}

\section{Results and discussion}

Figure 3 compares indentation load-displacement curves for the Berkovich indenter and non- and neutronirradiated state. As expected, harder irradiated material permits lower penetration depth with lower contact area. Maximum penetration depths together with directly observed contact areas and maximum pile-up heights for all six simulations are summarized in Table II. As can be seen, global material response expressed by the maximum penetration depth or projected contact area can be simulated using only a simple axisymmetric model without loss of accuracy. Maximum pile-up height is higher in case of irradiated state due to lower hardening exponent. It is more pronounced for the Berkovich indenter, for which the material piles up locally near the pyramid side (Fig. 4a). The pile-ups around the cone indenter are distributed evenly (Fig. 4b) and therefore, their height is lower (Fig. 5). The proper modelling of pile-ups requires a very fine mesh, since a $2 \mathrm{D}$ analysis with finer mesh leads to reasonably lower values compared to the $3 \mathrm{D}$ one.

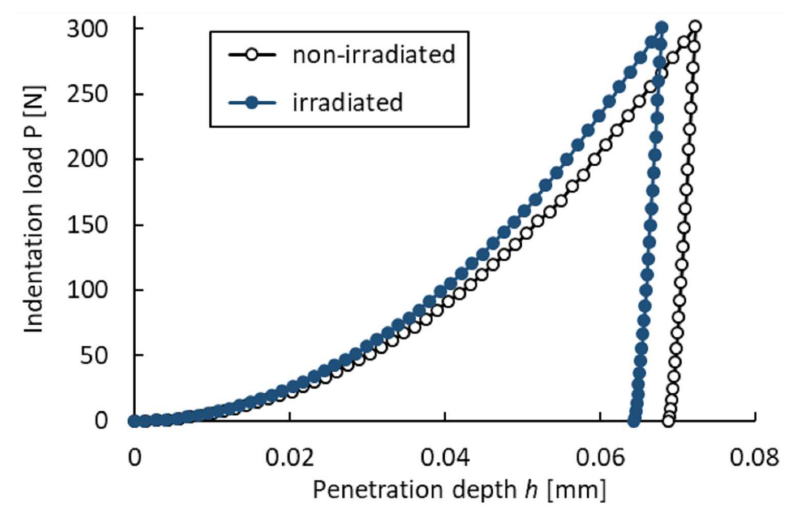

Fig. 3. Indentation load-displacement curves for the Berkovich indenter and non- and neutron-irradiated state.

Since the indentation load-displacement curves were close to all three geometrical representations of the indenter, only results of the axisymmetric simulation have been evaluated using the OP method according to (1) and (2). The predicted value of hardness for nonirradiated $15 \mathrm{Ch} 2 \mathrm{MFA}$ steel is $2564 \mathrm{MPa}$, which is in a (a)

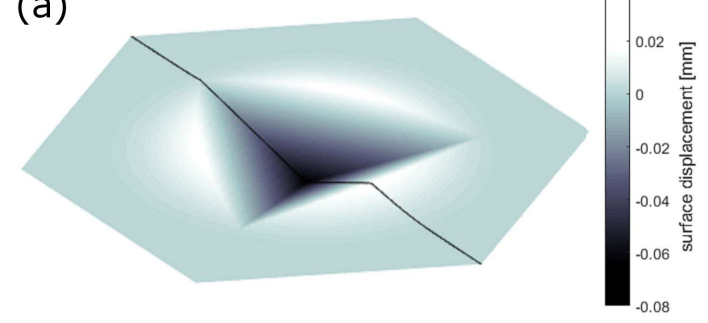

(b)

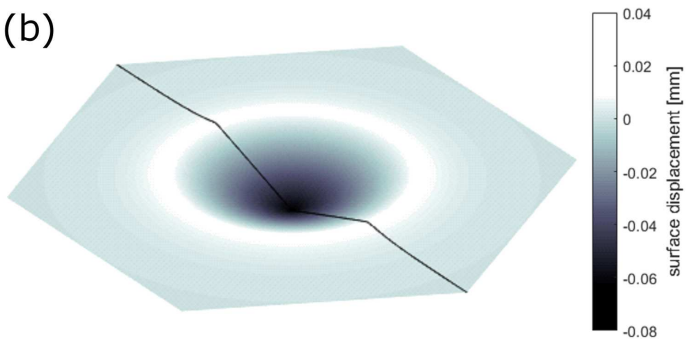

Fig. 4. Comparison of surface profiles for numerically indented neutron-irradiated 15Ch2MFA steel: (a) Berkovich indenter, (b) cone indenter. Light tones correspond to positive displacements, e.g. pile-ups. Surface lines represent section cuts for Fig. 5.

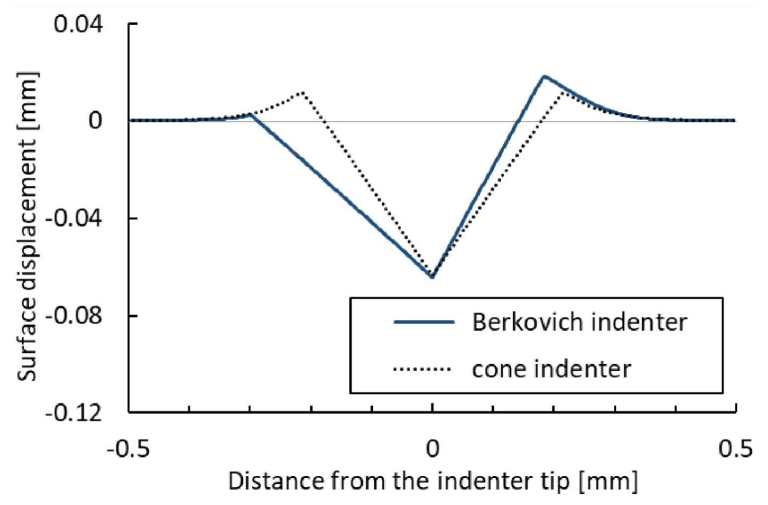

Fig. 5. Comparison of line profiles for Berkovich and cone indenter (neutron-irradiated 15Ch2MFA steel).

very good agreement with previous experimental measurements published in [14]. Contact areas $A_{\mathrm{OP}}$ resulted from the OP method underestimates "true" areas evaluated from finite nodes in contact (Table III). This leads to overestimation of hardness by factor of 1.32 and 1.40 for non- and neutron-irradiated state, respectively. 
Larger overestimation for irradiated material is related to a larger pile-up height. Ideally, in case of the same overestimation factors, a hardness measurement based on the OP data analysis procedure will still be reasonable for relative comparison of material properties change during irradiation or recovery after annealing. As can be seen from Table III, despite the small deviation in overestimation factors, the increase of hardness due to irradiation was indicated. Likely, it follows from the mutual link between the material properties affecting the pile-up formation: increase of the yield stress during irradiation, which decreases pile-ups, is compensated by the decrease of hardening exponent.

TABLE III

A comparison of alternatively estimated contact areas using two-dimensional axisymmetric analysis with conical indenter (used indexes: $n$ - non-irradiated, $i$ - irradiated, OP - the Oliver-Pharr method, $D$ - directly observed from finite element analysis)

\begin{tabular}{|c|c|c|c|}
\hline & \multicolumn{2}{|c|}{ Contact area $\left[\mathrm{mm}^{2}\right]$} & \multirow[b]{2}{*}{$\frac{A_{D}}{A_{\mathrm{OP}}}=\frac{H_{\mathrm{OP}}}{H_{D}}$} \\
\hline & $\begin{array}{c}\text { From the OP } \\
\text { method }\end{array}$ & \begin{tabular}{|c|} 
Directly \\
from FEA
\end{tabular} & \\
\hline non-irradiated & 0.117 & 0.155 & 1.32 \\
\hline neutron-irradiated & 0.102 & 0.143 & 1.40 \\
\hline$\frac{A_{n}}{A_{i}}=\frac{H_{i}}{H_{n}}$ & 1.15 & 1.08 & \\
\hline
\end{tabular}

\section{Conclusions}

The results of elastic-plastic finite element simulations of indentation of the reactor pressure vessel steel led to the following conclusion:

- The conical indenter with an equivalent cone apex angle is preferred for simulation of global deformation response instead of actual 3D Berkovich indenter in order to reduce the analysis time duration.

- Pile-ups can have important effects on the evaluation of contact area from indentation loaddisplacement curves. For instance, the OliverPharr method overestimates the hardness of neutron-irradiated steel 15Ch2MFA by $40 \%$ compared to direct observation of simulated contact area.
- Such estimated values of hardness are still able to describe the radiation embrittlement for steel and fluences investigated in this paper.

\section{Acknowledgments}

This work was supported by the Technology Agency of the Czech Republic, project No. TH02020565.

\section{References}

[1] G.R. Odette, G.E. Lucas, JOM 53, 18 (2001).

[2] A.M. Kryukov, Yu.A. Nikolaev, A.V. Nikolaeva, Nucl. Eng. Des. 186, 353 (1998).

[3] J. Marian, V.V. Bulatov, J. Nucl. Mater. 415, 84 (2011).

[4] C.S. Becquart, C. Domain, Metall. Mater. Trans. A 42, 852 (2011).

[5] A. Al Mazouzi, A. Alamo, D. Lidbury, D. Moinereau, S. Van Dyck, Nucl. Eng. Des. 241, 3403 (2011).

[6] V. Badanin, Y.G. Dragunov, V. Fedorov, I. Gorynin, V. Nickolaev, Nucl. Eng. Des. 133, 71 (1992).

[7] B.A. Gurovich, E.A. Kuleshova, A.S. Frolov, D.A. Maltsev, K.E. Prikhodko, S.V. Fedotova, B.Z. Margolin, A.A. Sorokin, J. Nucl. Mater. 465, 565 (2015).

[8] W.C. Oliver, G.M. Pharr, J. Mater. Res. 7, 1564 (1992).

[9] W.C. Oliver, G.M. Pharr, J. Mater. Res. 19, 3 (2004).

[10] I.N. Sneddon, Int. J. Eng. Sci. 3, 47 (1965).

[11] P. Haušild, M. Kytka, M. Karlík, P. Pešek, J. Nucl. Mater. 341, 184 (2005).

[12] P. Haušild, A. Materna, M. Kytka, J. Nucl. Mater. 459, 122 (2015).

[13] A. Bolshakov, G.M. Pharr, J. Mater. Res. 13, 1049 (1998).

[14] J. Nohava, P. Haušild, D.G. Axelson, G. Bolloré, Key Eng. Mater. 586, 59 (2014). 